\title{
TITLE:
}

\section{Toward a CO zero emissions energy system in the Middle East region}

$\operatorname{AUTHOR}(\mathrm{S})$ :

Farzaneh, Hooman; McLellan, Benjamin; Ishihara, Keiichi N.

\section{CITATION:}

Farzaneh, Hooman ... [et al]. Toward a CO zero emissions energy system in the Middle East region. International Journal of Green Energy 2016, 13(7): 682-694

ISSUE DATE:

2016

URL:

http://hdl.handle.net/2433/259768

\section{RIGHT:}

This is an Accepted Manuscript of an article published by Taylor \& Francis in International Journal of Green Energy on 26 July 2016, available online: http://www.tandfonline.com/10.1080/15435075.2014.889014.; この論文は出版社版であ りません。引用の際には出版社版をご確認じ利用ください。;This is not the published version. Please cite only the published version. 


\section{ACCEPTED MANUSCRIPT}

\section{Toward a $\mathrm{CO}_{2}$ zero emissions energy system in the Middle East Region}

Hooman Farzaneh ${ }^{*}$, Benjamin McLellan and Keiichi N. Ishihara

Graduate School of Energy Science, Kyoto University,Kyoto 605-8501,Japan

* Correspounding Author: email: info@hfarzaneh.com

Abstract: Climate change and energy security are global challenges requiring concerted attention and action by all of the world's countries. Under these conditions, energy supplier and exporter countries in the Middle East region are experiencing further challenges, such as increasing domestic energy demand while energy exports have to concurrently be kept at high levels. Middle East countries process the largest proven oil and gas reserves in the world and contribute a large fraction of the world's $\mathrm{CO}_{2}$ emissions from the use of these as fuels both domestically and internationally. This paper addresses different policies that could dramatically change the future course of the Middle East region towards a zero $\mathrm{CO}_{2}$ emission energy system. To this aim, an integrated energy supply-demand model has been developed to analyze required commitments include renewable energy and energy efficiency targets and the potential of nuclear power, all of which should need to be considered in order to reduce $\mathrm{CO}_{2}$ emissions by 2100 . The results indicate that nearly $43 \%$ of the global energy of the Middle East region can be supplied from non-fossil fuel resources in 2100.

Keywords: Middle East, Zero emissions, energy system, renewable energy, optimization model 


\section{ACCEPTED MANUSCRIPT}

\section{Introduction}

The Middle East contains a number of countries that are major players in the international oil and gas landscape as represented in table1(OPEC, 2011). Five countries (Saudi Arabia, Iran, the United Arab Emirates, Iraq and Kuwait) each produce more than 2 million barrels of oil per day, contributing by far the largest proportion of regional production. Saudi Arabia leads in terms of oil, as do Iran, Qatar, Oman and UAE in terms of natural gas. Bahrain has developed refining capacities which it runs by importing crude oil from Saudi Arabia and exporting the refined products. Iraq has decided to invite foreign companies to contribute to rebuilding its oil production potential. Given the impact of 30 years of war and embargo, many opportunities exist to revive old deposits using modern technologies and/or to develop Iraqi fields previously identified but yet to be brought into production. Iraq could potentially triple its production capacity to become a major producer and exporter. Iran is still the second-largest national oil producer in the Middle East, but the old deposits that provide the majority of current production would require a greater investment to offset their natural decline or to increase extraction levels.

The Middle East currently contributes $31 \%$ and $15 \%$ of total global crude oil and natural gas production, respectively (IEA, 2010). Gas production in the Middle East has increased considerably in the last 10 years, in contrast with oil production which has remained relatively unchanged. In some countries such as Saudi Arabia, this increase has been focused solely on meeting strong growth in local demand, whilst for others (Qatar, Iran, Oman and UAE), it has been a matter of boosting gas exports.

\section{ACCEPTED MANUSCRIPT}




\section{ACCEPTED MANUSCRIPT}

On the demand side, these countries have traditionally consumed a significant share of their own crude oil and natural gas production yet and this share of domestic consumption is increasing sharply, raising questions over the future of crude oil exports from Middle East countries. Increasing population, higher standards of living, accelerated growth of energy-intensive industries and highly-subsidized energy prices have led Middle Eastern demand for oil and gas to almost double.

Middle East countries may contribute a large fraction of the world's oil production but through their own energy consumption alone they produce approximately $6.4 \%$ of global $\mathrm{CO}_{2}$ emissions from fossil fuel uses (Boden et al. , 2011). The two major fuel consumers discharged 65\% of the region's fossil-fuel related $\mathrm{CO}_{2}$ in 2010: Iran, 146.8 million metric tons of $\mathrm{CO}_{2}$; Saudi Arabia, 118.2 million metric tons of $\mathrm{CO}_{2}$ (IEA, 2011). The oil producing nations in the Middle East, particularly those with small populations, such as Qatar and the United Arab Emirates (UAE), now rank among the world's worst performing countries in terms of per capita emissions. Qatar produces 55.4 tonnes of carbon per person- the highest global carbon footprint (El Hedi et al. , 2012). Qatar is followed by Kuwait which ranks as the third highest globally, with the UAE fourth and Bahrain fifth world highest in regards to the carbon footprint. Gas flaring has been a major source of regional emissions, and in a few years, before the infrastructure was available for gas use and injection, flaring accounted for almost half of the total fossil-fuel $\mathrm{CO}_{2}$ emissions. Growth has been nearly continuous since 1950, although it started from a very low base (Ramanathan, 2005). 


\section{ACCEPTED MANUSCRIPT}

While Middle-Eastern nations are often considered important from the point of view of energy security, they tend to go relatively unnoticed in regards to their domestic emissions. These nations ultimately have a significant potential to contribute to activities and gain benefits from climate mitigation policies by improving the sustainable development of their energy systems, whereas by not considering lowering their domestic GHG emissions they run the risk of external pressures taking full control of their trade environment.

In general, different kinds of renewable energy, increased energy efficiency and also the use of nuclear energy can reduce the use of fossil fuels and contribute to the reduction of GHG emissions, while carbon capture and storage (CCS) may also have a part to play. To assess the specific contribution of each of the options, country-specific conditions need to be taken into account. This means that GHG intensity, together with sector performance indicators and the respective potentials for various renewable and non renewable energies can help to identify the most promising emission reduction options for each country.

This study analyzes the effects of possible high-impact events that could dramatically change the future course of the Middle East region towards zero $\mathrm{CO}_{2}$ emissions energy systems. In this case, two scenarios are presented: the baseline scenario, and the zero emissions scenario. Assumptions about government policies are critical to both scenarios, therefore different possible policies have been considered. The projection period runs up to 2030 for the short term and up to 2100 as a long term prediction. The starting year is 2010 , as the historical data for the all countries in the Middle East region were available at that time. The zero emissions scenario incorporates the broad policy commitments and plans that have been announced by countries

\section{ACCEPTED MANUSCRIPT




\section{ACCEPTED MANUSCRIPT}

such as Iran, UAE and Saudi Arabia to tackle energy insecurity, climate change, local pollution and other energy-related challenges. Those commitments include support for renewable energy and energy efficiency targets and potential nuclear power plants to reduce greenhouse gas emissions by 2100 .

To analyze the scenarios, an integrated model of optimal oil and natural gas supply-demand has been developed for the Middle-East region including main producers such as Iran, Iraq, Kuwait, Qatar, Saudi Arabia, Oman and Bahrain. To this end, the Middle East region is considered to be organized in the form of a firm and appears in a market that is oriented towards establishing an effective energy system to produce oil and gas with minimum costs subject to technical, institutional and economical constraints.

\section{Modeling Framework}

There has been a resurgence in developing sophisticated integrated models to investigate one or more aspects of the technology-energy-environment-economy spectrum (Chedid et al., 2007; Brandt et al., 2010; Brandt, 2010; Clark et al., 1998; Guseo, 2011; Krichene, 2002). Policy makers need advice to determine which actions should be taken to reduce the environmental impacts of economic activities. In this case, modeling has proven to be a cost-effective way to avoid costly policy mistakes.

The proposed methodology has been based on the research on energy supply and demand models to present an integrated demand-supply model to cover the technology-energy environment-economy chain in resource-based energy exporting countries in the Middle East

\section{ACCEPTED MANUSCRIPT}




\section{ACCEPTED MANUSCRIPT}

region (Sadorsky, 2011; Eltony, 1996; Kiani and Pourfakhraei, 2010; Abu-Qarn and Abu-Bader; 2004).

Figure 1 shows the modeling framework employed to ensure the overall consistency and reasonableness of the oil and gas supply and demand estimates. The model explicitly takes into account the impact of macro and micro economics and reinvestment of the additional capacity requirement on supply-demand match.

\subsection{Demand Side}

The demand model estimates the energy demand in the different countries of the Middle East region. The model projects the macroeconomics and demographic data to estimate energy demand based on the oil products, natural gas and electricity consumption in the region.

Total energy demand, E, in each region at time period t, can be written as a function of gross domestic production per capita, GDP, energy price, $\mathrm{P}$, Trade, T and energy intensity per capita, EI as represented by the equation (1):

$E=G D P^{\alpha} P^{\beta} T^{\partial} E I^{\gamma}$

Taking natural logarithms of Eq.(1) and adding a random error term produces the following equation:

$\ln E=\alpha \ln G D P+\beta \ln P+\partial \ln T+\gamma \ln E I+U$ 


\section{ACCEPTED MANUSCRIPT}

Where, $\mathrm{U}$ is the random error term. The data set contains annual observation over the period 1980-2010. The source of energy demand and intensity data is the BP statistical report for 2010 (BP, 2010) while GDP and population are collated from the International Monetary Found (IMF) and the UN data bank respectively (IMF, 2011; UN, 2011).

The analysis of the Middle East energy demand should be used in suggesting appropriate energy and environmental policy to sustain economic growth as well as to improve the environmental quality for better living standards in the region. This entails that there is a tradeoff between the efficient use of energy including environmental quality and sustained economic growth in the long term. In this study, the following equation is used to represent the relationship between economic growth, energy intensity, financial development and $\mathrm{CO}_{2}$ emissions (Shahbaz; 2012):

$\ln C=a_{0}+a_{1} \ln E I+a_{2} \ln G D P+a_{3} \ln Y+\varepsilon_{1}$

Where $\mathrm{C}$ is the $\mathrm{CO}_{2}$ emissions per capita (measured in $\mathrm{kt}$ ) and $\mathrm{Y}$ is the financial development proxy by real domestic credit to the private sector per capita.

It has been presumed that rise in energy intensity will increase carbon emission and that an increase in economic growth is linked to high $\mathrm{CO}_{2}$ emissions in the base case. The impact of financial development will be negative means that the financial sector may act as a conduit toenabling firms to adopt advanced cleaner and environmentally friendly techniques to save the environment from degradation. The data on carbon emissions and financial development proxies

\section{ACCEPTED MANUSCRIPT}




\section{ACCEPTED MANUSCRIPT}

are collected from the World Bank database. Estimation of the equations (2) to (3) will provide estimates of long run elasticities but in the context of panel estimation the ordinary least squares (OLS) estimator of these equations is asymptotically biased and its distribution depends upon nuisance parameters. The nuisance parameters are regressors that are not part of the true data generating process but could introduce unwanted endogeneity and serial correlation which is assumed to be normally distributed with zero mean and constant variance.

\subsection{Supply side}

The estimated energy demand is used as a defined parameter in the supply model to estimate oil and gas supply in the short and long terms. The economic rationality of a producer and activity of a firm has been extensively developed as a branch of microeconomics and it has been utilized for explaining the development of production technology. In this case, the Middle East region can be supposed to be organized in the form of a firm and appears in a market that is oriented towards establishing an effective energy system which may be identified as producing oil and gas with minimum total cost subject to satisfying the demand, export requirement and other technical, economical and institutional constraints. This concept may be formulated as below (Farzaneh et al., 2012; Farzaneh and Dashti, 2010):

$\operatorname{Min} T C=\sum_{t} \beta_{m}^{t} \Delta t\left\{\begin{array}{l}\sum_{v} \sum_{l} \sum_{f}\left(E_{f v l t} \eta_{f v l} C V_{f v l t}\right)+\left(Y_{f v l t} C F_{f v l t}\right)+\sum_{\tau=t-\tau_{f l v t}}^{t}\left(Y_{f v l \tau} C F_{f v l t}\right) \\ +\sum_{r}\left[\sum_{g} \sum_{l} R_{r g l t}\left(c_{r g l t}+x_{r g l t}\right)+\sum_{c} \sum_{l}\left(I_{r c l t} c i_{r c l t}\right)-\sum_{c} \sum_{l}\left(E_{r c l t} c e_{r c l t}\right)\right]\end{array}\right\}$

Subject to : 


\section{ACCEPTED MANUSCRIPT}

A)Demand Constraint:

$\sum_{f v l t} \eta_{f v l t} E_{f v l t} \geq E_{f v l t}^{*}$

Where, $\eta, E^{*}$ represent efficiency and defined energy demand for energy carriers $\mathrm{f}$ through using technology $\mathrm{v}$ in each region during the load region 1 and time period $\mathrm{t}$.

B) Capacity Constraint on production

$\frac{E_{f v l t} \eta_{f v l t}}{\Delta l} \leq \sum_{\tau=1}^{t} Y_{f v l \tau} P F_{f v l \tau}+\sum_{\omega=b-((P L-t))}^{b} Y_{f v l \omega} P F_{f v l t}$

Where PF and PL are plant factor and plant life of each sub-system.

C) Availability of resources:

$\sum_{r g l t} R_{r g l t}-\sum_{f v l t} E_{f v l t} \geq 0$

Where, $g$ is the cost grade of the energy resource. $R$ is energy resource for carrier $f$ in each region during the load region 1 and time period $t$.

D) Speed of resource extraction:

$R_{r g l t} \leq \alpha\left(U R R-\sum_{\tau=1}^{t-1} R_{r g l \tau}\right)$ 


\section{ACCEPTED MANUSCRIPT}

$\alpha$ is the percentage of remaining resource that can be extracted in a year. This constraint governs the overall shape of increasing and decreasing production of a resource, representing a peak oil curve of resource depletion. URR is Ultimate Recoverable Resource.

E) $\mathrm{CO} 2$ Emission constraint:

$\sum_{f v l t}\left(\eta_{f v l t} E_{f v l t}\right) \phi_{f v l t t} \leq \phi_{f v l t t}^{*}$

Where, E represents the energy flow through the different levels of the system. $\phi$ and $\phi^{*}$ are emission factor and emission upper limit of technology $\mathrm{v}$.

Also in Equation (4), $\beta$ is the discount factor in the period t. $c_{r g l t}, c i_{r c l t}, c e_{r c l t}$ and $x_{r g l t}$ indicate the unit price of: resource, import, export and externalities such as carbon tax in each region. I and E represent import to and export from each country (c), respectively.

In the Middle East region, utilization of a field of crude oil or natural gas follows the the physical characteristics of the field. According to equation (8) production varies as a function of the accumulated extraction of oil and gas fields. It is usually stated that production from a field rises in the initial stages, when the accumulated extraction is low. It reaches a plateau (maximum production) at certain stages of the life of the field, then, when the field is has been worked for some time, a decline in production level is observed as the accumulated extraction increases. The pattern of production of rich gas from a field may be described according to the Hubbert peak oil theory as follows (Nashawi et al., 2010): 


\section{ACCEPTED MANUSCRIPT}

$$
\begin{aligned}
& R=\sum_{i=1}^{k}(R)_{i}=\sum_{i=1}^{k} 4\left(R_{\max }\right)_{i}\left\{\frac{e^{-\alpha\left(t-t_{\max }\right)}}{\left[1+e^{-\alpha\left(t-t_{\max }\right)}\right]^{2}}\right\}_{i} \\
& \alpha=4 \frac{R_{\max }}{U R R}
\end{aligned}
$$

Where in the above equations, $k, t_{\max }$ and $R_{\max }$ are defined sequentially as number of defined cycles for peak estimation, peak time and peak production of the resource.

\section{Description of scenarios and data}

\subsection{Baseline Scenario}

The baseline scenario was developed to show how the future might look on the basis of the perpetuation of current policies in the Middle East region. Therefore, the model uses historical trends of demographic and energy related data in the Middle East region to project the energy demand/supply in the short and long terms.

\subsubsection{Main macroeconomic assumptions:}

- $\quad$ The region's population has grown from 83 million in 1970 to 191 million in 2010. Projections from the UN shows an average annual population growth of around $1.9 \%$ from 2010 to 2030 .

- $\quad$ Projections from the IMF show global gross domestic product growing by around $4.1 \%$ in 2010. The GDP is projected to grow an average of 3.5\% per annum from 2010 to 


\section{ACCEPTED MANUSCRIPT}

2030 and by around $2.4 \%$ from 2030 to 2100 . The aforesaid growths are estimated on the basis of the relationship between GDP per capita and population in the Middle East region.

- $\quad$ Energy intensity is assumed to increase 1.5\% annually from 2010 to 2030 in the Middle East region. However, there are regional differences in energy intensity. Iran, Iraq and Saudi Arabi are expected to increase their energy intensity while UAE shows a steadying of growth in its energy intensity. The long term projection of energy intensity average annual growth rate with current policies is assumed to be around $1.3 \%$ up to 2100 across the region.

- $\quad$ Oil price is assumed to rise steadily to 2030 as rising global energy demand requires the development of increasingly expensive sources of crude oil (NRC, 2011). Natural gas price has been closely correlated to the oil price in long term oil supply, although in reality this may change with the introduction of shale gas and coal bed methane into the supply mix. The natural gas price is assumed on the basis of import prices in different regions such as USA, Europe and Japan (BP, 2012).

\subsubsection{Long term projection of energy demand and supply}

Taking realistic oil and gas production curves into consideration, most Middle East countries will lose their status as net energy exporting countries before 2050. The point at which consumption and production reach the same value represents the so-called "crude oil/ natural gas equivalence 


\section{ACCEPTED MANUSCRIPT}

point". Figure 2 shows the equivalence points for selected countries in the Middle East region up to 2100 .

Decades before these equivalence points, Middle East countries will experience more severe consequences of high energy consumption and sinking production of fossil fuels and export revenue will decrease. The trend is the same for natural gas, with one major exception: owning the world's second largest gas reserves, production can be increased considerably in coming years. However, natural gas consumption is growing faster than oil product consumption, and the Middle East is likely to become a large net importer of natural gas before 2060. Currently, the majority of Middle-Eastern electricity generation and heat production is from natural gas. Hydropower contributes only a little to the electricity sector and only in Iran and Iraq, and renewable energies generally haven't played a role in energy system planning in the Middle East.

\subsubsection{Projection of $\mathrm{CO}_{2}$ Emissions up to 2100}

For the baseline scenario, the $\mathrm{CO}_{2}$ emissions will increase from 7.6 tonnes per capita in 2010 to 11.7 tonnes per capita in 2030 and 27 tonnes per capita up to 2100 . The relationship between $\mathrm{CO}_{2}$ emissions and energy intensity is demonstrated in Figure 3.

The baseline scenario which has been based on the demographics and socioeconomic historical trends demonstrates the situation that could occur due to aberrant consumption of fossil fuel resources in the Middle East region in the short and long terms. Given that technological changes may occur in the Middle East energy system in the near future, another scenario may be defined as the "zero emission" future for this region, which will be analyzed in the next section.

\section{ACCEPTED MANUSCRIPT}




\section{ACCEPTED MANUSCRIPT}

\subsection{Zero $\mathrm{CO}_{2}$ emission scenario}

There is a growing recognition of the linkages between climate change and energy security in the Middle East region. Policies and measures that address both issues have the potential to provide significant social and economic benefits. The transformation of traditional energy systems away from fossil fuel use offers significant climate protection benefits, but also offers synergistic reduction of localized pollutants. Middle eastern nations have yet to fully take a part in the responsibility to avoid dangerous climate change. These nations are able to contribute to activities and receive benefits from climate mitigation policies by improving the sustainable development of their energy system. Given the relative abundance of fossil fuels in the region, convincing governments to take such action is a challenging task.

Two main factors are seen as being able to contribute to decreasing the $\mathrm{CO}_{2}$ emissions of Middle East countries: energy productivity improvements and changing to energy sources with lower $\mathrm{CO}_{2}$ emission factors (e.g. gas, renewables, nuclear). To this aim, the zero emission scenario has been developed to study the effect of these two factors on reducing $\mathrm{CO}_{2}$ emissions toward a target of zero emissions by 2100 .

\subsubsection{Availability of renewable energy resources in the Middle East Region}

The Middle East region possesses huge solar energy potential which could readily be harnessed using concentrating solar power technologies. This is especially important given the urgent need to remove fossil fuels from the energy system of this region. While solar power systems are scalable from some $\mathrm{kW}$ to some hundred $\mathrm{MW}$, the system vulnerability could be contained by

\section{ACCEPTED MANUSCRIPT}




\section{ACCEPTED MANUSCRIPT}

installing small and decentralized plants. In this case, PV solar panels are recommended to replace the fossil-based power plants in the Middle East countries. If electricy is considered for export from the Middle East region to Asia and Europe on a large scale, larger plants using concentrating solar power (CSP) would have to be built. The Middle East region presents abundant solar potential which has only been exploited to a limited extent for electricity production. Total economic potential for use of solar energy was calculated by DLR (German Aerospace Center) via satellite imaging (DLR, 2005). In some countries such as Iran and Saudi Arabi utilizable surfaces are exceptionally large and would be ideal sites for solar power generation in the future.

Iran is the only country in the Middle East region with any large scale wind farm installations. There are plans for expanding wind turbine capacity to reach $400 \mathrm{MW}$ in coming years. The country currently has two wind farm plants, with a combined capacity of $92 \mathrm{MW}$. Total economic potential for use of wind energy in the Middle East Countries is calculated to be about $13 \mathrm{TWh} / \mathrm{y}$ in Iran and less than $6 \mathrm{TWh} / \mathrm{y}$ in Oman (WEC. 2007).

Also, Iran is the only nation with high geothermal potential in the Middle East region with an economic potential about $30 \mathrm{TWh} / \mathrm{y}(\mathrm{SABA}, 2005)$. As geothermal hot spots are far from inhabited areas, heat is unlikely to be used directly, therefore only the electrical generation option remains for geothermal energy utilization in this region.

Hydropower is used to a small extent in Iran and Iraq, producing less than $10 \mathrm{TWh} / \mathrm{y}$ (SABA, 2006). But there are plans to increase hydropower contributions to the electricity mix in these

\section{ACCEPTED MANUSCRIPT}




\section{ACCEPTED MANUSCRIPT}

countries. The World Energy Council estimates these two countries' potential to be $50 \mathrm{TWh} / \mathrm{y}$ in Iran and $67 \mathrm{TWh} / \mathrm{y}$ in Iraq respectively (WEC, 2008).

\subsubsection{Implementation of zero emissions policy in the Middle East Region}

\subsubsection{1. $\underline{\mathrm{CO}}_{2}$ emission reduction potential in mid and long terms}

The Middle East region has shown remarkable growth in total fossil-fuel $\mathrm{CO}_{2}$ emissions during recent decades. In 2010, total emissions reached an all-time high of 7.7 metric tonnes of $\mathrm{CO}_{2}$ per capita. Approximately 60 percent of the total $\mathrm{CO}_{2}$ emissions came from the end-user (industrial sector, transport sector and residential \& commercial sector) activities and the remaining 40 percent comes primarily from the energy (fuel and electricity) production sectors. Transportation is the largest end-use source of carbon dioxide and most $\mathrm{CO}_{2}$ is emitted as a result of using fossil fuels. This means that reducing $\mathrm{CO}_{2}$ emissions requires assertive action in all energy sectors in this region. For the energy system of the Middle East region, there essentially are three major methods to reduce $\mathrm{CO}_{2}$ emissions:

1- Use fuels with lower $\mathrm{CO}_{2}$ emissions per unit of electricity produced. In this case, using natural gas to produce electricity instead of oil products has been considered as a policy action to reduce $\mathrm{CO}_{2}$ emissions in the power sector of Middle Eastern countries.

2- $\quad$ Increase the efficiency of both energy production and end-use.

3- Capture and permanently store $\mathrm{CO}_{2}$ emissions. 


\section{ACCEPTED MANUSCRIPT}

These methods should be applied in the Middle East's energy system by increasing the use of Carbon Capture and Storage (CCS) technology, renewable energy and nuclear power, and by reducing the carbon footprint of fossil power in the end-user sector. Carbon capture and storage plants are adaptable to use in power generation and desalination sectors. The Middle East is one of the most attractive regions in the world for the deployment of large scale CCS facilities. One driver is the presence of vast oil and gas fields, which offer excellent potential as $\mathrm{CO}_{2}$ storage sites. The volume of oil and gas extracted from the Middle East region to date suggests pore space of very high capacity is available. Most of these fields are still producing and at current production rates, are expected to continue production for many years, making access to $\mathrm{CO}_{2}$ storage in the near term unlikely. However, as fields deplete the available volume and probability of access increase, making the Middle East region a large, long term $\mathrm{CO}_{2}$ storage possibility.

Figure 4 shows the assumed $\mathrm{CO}_{2}$ emissions reduction potential from the zero emissions scenario which has been considered as a pre-defined parameter in developing the model. Accordingly, about $35 \%$ reduction in $\mathrm{CO}_{2}$ emission is assumed through improving energy efficiency and diffusing CCS technology up to 2030 . From 2030 to 2050 , another $25 \%$ reduction is assumed to occur with further utilization of CCS technology and other renewable energies and finally, the zero emissions target will be achieved with the sustainable expansion of renewable and nuclear energies in 2100 .

\subsubsection{Energy efficiency improvement potential in the mid and long terms}

Energy is used very inefficiently in the Middle East region compared to other regions of the world. Energy efficiency is an option for this region to enter a sustainable development path, and

\section{ACCEPTED MANUSCRIPT}




\section{ACCEPTED MANUSCRIPT}

low energy consumption is a key to reduce dependence on imported gasoline. Depending on the time frame for implementation, there are large cost-effective saving potentials in energy consumption in this region.

One of the main reasons of high energy intensity in the Middle East region is the subsidization of energy. Thus for a broad implementation of energy efficiency measures to be successful, a reduction in energy subsidies is essential. It is assumed that in the short to mid term Middle Eastern nations will abolish direct final energy subsidies and allow for undistorted competition in their energy system.

Improvement in energy efficiency and reduction in energy intensity will be possible through the implementation of measures that: remove energy subsidies, facilitate the penetration of energyefficient equipment and appliances; establish energy services companies; develop appropriate financing mechanisms; introduce tighter building codes; better manage electricity loads; and reduce electricity losses and gas flaring.

Based on the above measures, by formulating integrated policy in the Middle East region, improvement in energy intensity is assumed to be realized to about $30 \%$ in the mid term and about $60 \%$ in the long term.

\subsubsection{Costs and cost reduction in the mid and long term}

Figure 5 gives "learning curves" of the specific investment cost for power generation technologies including CCS technologies and renewable energies today and in the future which have been used in developing the model, based on (Tidball, et al., 2010). Capital investment for

\section{ACCEPTED MANUSCRIPT}




\section{ACCEPTED MANUSCRIPT}

renewable energies are expected to remain more expensive than those for fossil fuel power plants with the exception of wind and photovoltaics. In the case of CCS, various estimates of current costs (and future cost forecasts) have been obtained from the literature which vary in regard to project-specific factors including:

- $\quad$ The type of capture technology to be employed.

- $\quad$ The purity of the $\mathrm{CO}_{2}$ and the ease of its capture which in turn depends on the specifics of the $\mathrm{CO}_{2}$ source.

- $\quad$ The scale and design of the CCS facility.

- $\quad$ The type of $\mathrm{CO}_{2}$ storage

Conventional fossil power plants cause specific external costs in the range of 5 to $10 \$ / \mathrm{kWh}$ (Tidball, et al., 2010). External costs of renewable energy technologies are between 0.1 to 1 $\$ / \mathrm{kWh}$ thus about one order of magnitude below those of fossil technologies. It means that with full internalization of external costs, renewable energy technologies are compatible with conventional power plants already today. External costs of nuclear energy have been considered as risk insurance about $5 \$ / \mathrm{kWh}$ (Wuppertal, 2009).

\subsubsection{Lead time for the construction of new technologies}

Renewable energy technologies have a lead time of 5 years. By comparison, the evaluation of worldwide nuclear energy projects shows that with more than 10 years, this technology has the longest lead time of all technologies under consideration. Operation of both nuclear and

\section{ACCEPTED MANUSCRIPT}




\section{ACCEPTED MANUSCRIPT}

renewable plants requires few, but very highly qualified (particularly for nuclear), technicians and engineers due to the very high degree of automation. Currently, Middle East nations do not have significant expertise in nuclear technology and it is very ambitious to establish such expertise in a short time. Moreover, global concerns over nuclear proliferation would undoubtedly require significant oversight be applied to allow development of nuclear power infrastructure.

Accordingly, utilization of nuclear energy in the Middle East region may be considered to have a lead time of 20 to 30 years when the lack of knowledge about this technology and expertise are also included. This assumption was considered in developing the supply model, with the exception of Iran which has started to run a 2000 MW nuclear power plant in Boushehr since 2012.

\subsubsection{Assessment of technologies in the Middle East region}

Assuming population and economic growth projections almost the same as the base scenario, and considering the energy intensity improvements in the mid and long terms, domestic energy demand for the zero emissions scenario compared to the baseline scenario is shown in Figure 6. As the figure shows, based on the zero $\mathrm{CO}_{2}$ emissions scenario, domestic energy consumption is about $7.5 \%$ less annually on average than the baseline scenario in 2030 . This gap increases to $15.5 \%$ in 2050 and $38.2 \%$ in 2100 .

The zero $\mathrm{CO}_{2}$ emissions scenario is developed to clearly express those policies which lead to further increase the share of renewable and nuclear energies in the Middle East energy system.

\section{ACCEPTED MANUSCRIPT}




\section{ACCEPTED MANUSCRIPT}

The make up of electricity demand in the mid and long terms across the different technologies is illustrated in Figure 7. The energy and environmental policies which are considered in the zero emissions scenario have particularly strong impact on the outlook for CCS technology, renewable energy and nuclear power generation.

Based on the zero $\mathrm{CO}_{2}$ emissions scenario results, natural gas CCS power plants (NG-CCS) represent nearly $12.2 \%$ of the energy mix in 2015 . About $70 \%$ of total conventional fossil power plants should gradually be replaced by modern Oxy-fuel-CCS power plants up to 2030. In regards to nuclear fuel, the Middle East region's uranium ore deposits are limited, meaning that the enriched uranium should be considered as an import to this region in future. The price of $4 \%$ enriched uranium has been considered to start from $3000 \$ /$ b in 2010 and to double its value by 2100. In the short term, the share of nuclear energy is negligible in the energy mix because of its long lead time (only Boushehr atomic plant in Iran). The share of solar energy in total electricity demand in the Middle East region increases to more than 7\% in 2030.

Municipal solid wastes represent the most likely source of biomass in Middle East countries but its potential is limited. The major biomass producing country is Iraq, however the share of biomass energy in power generation does not rise above $3 \%$ due to its high investment costs and required land compared with NG-CCS power plants. As mentioned earlier, Iran and Iraq have sufficient hydropower potential. These countries are projected to increase their hydropower capacity to nearly its maximum around $18 \mathrm{GW}$ in the mid term.

In the long term, from 2050 to 2100 , the share of nuclear energy is projected to increase to about $30 \%$ while solar-generated electricity will represent nearly $25 \%$ of the energy mix in 2100

\section{ACCEPTED MANUSCRIPT}




\section{ACCEPTED MANUSCRIPT}

(Figure 8). This means that nuclear energy begins to develop in the mid to long term in the Middle East region but its growth will be limited due to concerns over construction delays, higher than expected investment costs in some countries and a return to lower natural gasprices.

Solar power technologies are anticipated to undergo cost reduction globally. Solar photovoltaic plants are technologically rather mature, nevertheless costs will be reduced by economies of scale. Solar power technologies would, however, have to be subsidized in the Middle Eastern nations in the short term.

The energy mix in the power sector of 8 selected countries of the Middle East is shown in Figure 9. As can be observed from the energy mix diagrams in the power sector of the Middle Eastern countries, the region's fast-growing power demand will increasingly be met with the aid of advanced technologies: CCS, Solar and nuclear power plants enabling the Middle East to realize a more sustainable power sector for the future. CCS is certainly an important option to be considered in this region as it can be utilized for enhanced oil recovery as well as reducing $\mathrm{CO}_{2}$ emissions.

$\mathrm{CO}_{2}$ injection can also replace the need to reinject associated gas for enhancing oil recovery. Compared with baseline scenario therefore, more natural gas will be available after 2080 to meet domestic energy consumption in the oil producing countries in this region. In the near term, deployment in the upstream sector is likely to be dominated by low-cost opportunities in natural gas processing, notably from high- $\mathrm{CO}_{2}$ gas fields in regions such Iran, Qatar, Oman and UAE. Capture from industrial and upstream sources will account for around $45 \%$ of the Middle East CCS technology deployment in 2100 due to improving technology and capture efficiency.

\section{ACCEPTED MANUSCRIPT}




\section{ACCEPTED MANUSCRIPT}

Some Middle Eastern nations should be more active than others in harvesting solar energy due to their high domestic energy consumption and lack of other renewable energy resources. In this case, Kuwait and Bahrain are net energy exporters with limited oil and gas reserves and the results show that solar electricity should be developed in their power sectors before 2030 . In the case of Iran and Iraq, with the largest resources of hydro in the Middle East region, these countries will be the pioneers of hydropower generation in the mid term. In these countries, solar electricity will enter the power sector only after 2030.

\subsubsection{The effect of rising natural gas price on the energy demand mix}

The low density of natural gas makes it more costly to contain and transport than either crude oil or oil products in the Middle East region and if there are no market outlets, the gas often has to be consumed as domestic energy in this region. This region has the highest reserves in the world, however, the gas producing countries are facing challenges regarding these gas supplies:

- Are the reserves sufficient to sustainably feed export projects?

- Does the increasing domestic demand in the region allow for additional export projects?

- Do the LNG and pipeline gas suppliers have a stable political environment and the financial strength to engage in further LNG and pipeline export projects?

Based on the results of the baseline scenario, the Middle East region has sufficient reserves for natural gas production up to 2100. However, because all this region's countries have high

\section{ACCEPTED MANUSCRIPT}




\section{ACCEPTED MANUSCRIPT}

domestic consumption combined with high energy intensity, the possibility of natural gas exports will be reduced after 2080 .

On the other hand, the zero emissions scenario estimates that natural gas will replace domestic consumption of oil products in the power sector at a higher rate, but more efficiently, than the baseline scenario. In this case, gas market prices can be considered as a stimulus for more competition with other alternative technologies (such as solar and nuclear energies) and NG-CCS technology in the mid and long terms. If there is upward pressure on the natural gas market price, the make-up of the technologies in the power sector may be changed in the future. To examine the effect of a rising natural gas price on the energy demand mix in the power sector, two market price modes (a high rate of $4 \%$ and a low rate of $1 \%$ increment per year on average from 2035 to 2100) have been considered in the zero emissions scenario as depicted by Figure 10.

Figure 11 shows the natural gas export projections on the basis of the low price scenario. As the figure shows, the maximum export will be about 466 billion cubic metres per year around 2045 . Considering the higher price scenario, more LNG facilities with improvemed technology and cost performance are required to export more natural gas. It is noteworthy that the LNG market is not - nor will it ever be - as flexible as the world oil market. The high costs of LNG manufacturing and transportation still make it difficult to move the commodity physically over long distances. LNG projects represent a 'chain' of investments consisting of field development, liquefaction facilities, transportation and the regasification terminal. Costs throughout the value chain have been declining in the LNG industry in recent years, but LNG projects are still among the most expensive energy projects. Accurate data on LNG plant costs are difficult to pinpoint

\section{ACCEPTED MANUSCRIPT}




\section{ACCEPTED MANUSCRIPT}

since costs vary widely depending on location . According to an independent LNG consultant, the construction of an LNG plant costs at least $\$ 1.5$ billion per $1 \mathrm{mtpa}$ (Million tons per annum) capacity, a receiving terminal costs $\$ 1$ billion per 1 bcf/day throughput capacity, and LNG vessels cost \$200-300 million (Carnot, et al., 2010). LNG shipping costs are determined by the daily charter rate, which is a function of the price of the ship, the cost of financing, and operating costs.

The trade-off between recoverable revenue from exporting $\mathrm{LNG}$ and required capital investment to improve the gas production sector has been considered in the supply model. If the market price is set to high rate mode, LNG technology plays a more effective role in the upstream sector and therefore, more natural gas will be released to export. As Figure 12 depicts, with the high price mode, the share of NG-CCS technology in the power sector remains constant past 2050 while its share will be replaced by solar and nuclear energies in the long term. However, the replacement level will be controlled by the required capital investment for LNG production and the recoverable revenue from selling natural gas in the international market. It is noteworthy that the price modes are considered as pre-assumptions in the model and market mechanisms are not included in

\subsubsection{Primary energy supply}

The projection of primary energy supply for the zero emissions scenario is shown in Figure 13. The share of total renewable energies and nuclear energy will represent nearly $43 \%$ of the global energy mix of the Middle East region in 2100.

\section{ACCEPTED MANUSCRIPT}




\section{ACCEPTED MANUSCRIPT}

According to the zero emissions scenario, a significant share of the oil production will be exportable in the mid term. This will be possible through improving energy efficiency on both the supply and demand sides and switching from consuming oil products to natural gas consumption. Also, by utilizing $\mathrm{CCS}$ technology, the captured $\mathrm{CO}_{2}$ will be available to inject and extract more oil from mature fields. This means that more associated natural gas will be available from the upstream to meet the domestic demand after 2070.

\section{Future Policies}

Current energy policy in the Middle Eastern nations is the result of past energy policies and subsidies that largely persist into the present, rather than considering future non-resource limitations. Fossil fuel prices are not the result of free market mechanisms, nor do they reflect the true costs. Such market distortions build up serious and pervasive barriers to zero emissions scenarios. Policies and measures have to cope with these realities and must not only overcome the barriers, but also provide an enabling environment for the sustainable growth of the energy system in this region. Deployment of the zero emission scenario in the Middle East region requires the following policies:

\section{i) Reforming energy subsidies}

Energy subsidies should be removed for the energy system of the Middle East region in the near to mid term. Subsidies often lead to increased levels of consumption and waste, as well as subsequent environmental pollution. Fuel subsidies account for a striking one-third of the total costs in the Middle east region. Rapidly rising domestic consumption, exacerbated by the

\section{ACCEPTED MANUSCRIPT}




\section{ACCEPTED MANUSCRIPT}

availability of the cheapest fuel in the world, has transformed the region's energy market with big crude exporters such as Saudi Arabia and Iran consuming more of their oil and gas at home. Reforming the energy subsidies plays a key role in moving the Middle Eastern nations into a more sustainable development path of energy production and consumption.

ii) Improving energy efficiency

Energy efficiency should be promoted in the industrial and residential sectors of the Middle Eastern countries by using more efficient materials and devices and also switching to renewable and clean sources of energy. Energy use in buildings accounts globally for nearly $40 \%$ of global energy consumption and $36 \%$ of total energy related- $\mathrm{CO}_{2}$ emissions in this region. The development of energy efficiency standards in the household sectors of Middle East countries should be considered as one of important parts of the zero emissions policy. The use of energy efficient transport must be regulated through fiscal incentives, increasing fuel prices, and better traffic management. Also, the mere availability of renewable energy resources, incentives, technology, capital, expertise and government policy will not suffice if there is insufficient enduser awareness. Hence, the general peoples' awareness will be needed to be improved in this region.

iii) Priority of electrification in industrial and residential sectors

In the Middle East region the priority of electrification should be considered for productive uses (industry, household). Electricity usage is more efficient and cleaner than fossil fuel alternatives

\section{ACCEPTED MANUSCRIPT}




\section{ACCEPTED MANUSCRIPT}

for energy services and also enables the use of clean energies such as solar and nuclear energies instead of fossil fuels in the power sector. According to the zero emissions scenario, nearly all of the fossil fuel consumption in the household sector could be replaced by clean electricity which

has been produced through using CCS, solar and nuclear technologies in the power sector and it could facilitate the aim of zero $\mathrm{CO}_{2}$ emissions in the energy systems of the Middle East region.

iv) CCS technology as a cornerstone of zero emissions policy

CCS technology could provide a technological bridge for achieving near to mid term CO2 emissions reduction goals in the Middle East region. The application of CCS depends on the cost and readiness of capture technologies. NG-CCS with oxyfuel combustion results in streams with high concentrations of $\mathrm{CO}_{2}$, which are suitable for transport and storage after particulate and contaminant removal, optional flue gas desulphurisation and water removal. Utilization of captured $\mathrm{CO}_{2}$ emissions could enable EOR to provide more crude oil and support future exports from the Middle East. In addition to enhanced energy security benefits and revenues, $\mathrm{CO}_{2}$-EOR has potential to advance $\mathrm{CO}_{2}$ capture technology and build the necessary infrastructure for largescale $\mathrm{CO}_{2}$ storage in this region. $\mathrm{CCS}$ in this region will thereby become to CCUS (Carbon Capture, Utilization and Storage) and presents the Middle Eastern nations (as oil-rich countries) with a unique opportunity to both reduce their $\mathrm{CO}_{2}$ emissions levels and address the issue of oilfield depletion. Also, the advantages of freeing natural gas through replacing it with CCUS, along with the potential revenues that could be generated from increased oil production, are estimated to be enormous. It is evident that switching from the baseline to the zero emissions scenario increases the need for natural gas consumption in the power sector and by using CCUS

\section{ACCEPTED MANUSCRIPT}




\section{ACCEPTED MANUSCRIPT}

more associated gas will be available to use through the domestic gas network and if the high rate price mode is selected, these nations can outweigh the costs associated with constructing and operating the CCUS plants by increasing their gas exports in the future. It is noteworthy that successful deployment of CCUS is largely dependent upon the cost of $\mathrm{CO}_{2}$ capture and the existence of a supportive regulatory and policy environment which should be considered in developing the zero emissions policy in this region.

v) Solar electricity as a booster of electrification

The large space combined with the abundant solar resources and more limited potential for other renewable energy sources (with the exception of hydro potential in Iran and Iraq) has made the Middle East region one of the promising areas for the installation of solar energy plants for providing electricity in the power sector. Despite huge efforts, the electrification rate through the interconnected grid has not increased the overall electrification rate of the Middle East countries significantly. Some of these countries have made efforts on increasing their rural electrification rates however, due to the long distances and the harsh conditions, the expansion of high voltage networks for serving a few dispersed customers is a costly task for minimal overall benefit. The introduction of decentralized generation by using solar PV in urban and rural areas can be considered to improve this situation. The lessons from developed countries, has shown that the use of distributed generation based on solar energy, mainly PVs, can help significantly in improving, at competitive cost, the electrification rate with concrete social benefits to the local population.

vi) Nuclear power plant proliferation in the long term

\section{ACCEPTED MANUSCRIPT}




\section{ACCEPTED MANUSCRIPT}

Nuclear energy is unlikely to meet the Middle East region's rapidly growing energy demand. This region is experiencing a massive increase in energy consumption. With lead times for the construction of nuclear power plants between 8 and 12 years (and often significantly longer), it seems unrealistic that nuclear energy would be able to provide enough energy to satisfy the region's rising energy demand in the short to mid terms. The high investment costs and subsequent financial risks of nuclear power plants are substantially higher than those of NG-CCS powered plants. Switching from the baseline to zero emissions scenario, the carbon balance of the entire nuclear power cycle shows better performance as compared with natural gas and other renewable technologies. Also, in contrast to some renewables, the capacity and life time of nuclear plants is better and which leads to the selection of nuclear power to serve as one of the appropriate technologies in the power sector for the long term (after 2050).

\section{Conclusions}

In the coming decades, the use of energy in the Middle east region confronts society with new challenges for which new strategies have to be developed. The potential consequences of climate change, the depletion point of oil and the re-concentration of crude oil production in the Middle East demands more efficient use of energy resources. The Middle East region holds sufficient potential for renewable (Solar, hydro) energy, but at present, these technologies contribute only a mere one per cent to the region's primary energy mix. In addition to environmental and other benefits, these types of technologies have a long-term economic advantage over non-renewable energy carriers. Embracing the benefits and deploying renewable energy requires the adoption of appropriate policies such as a zero emissions policy in this region. According to zero emissions

\section{ACCEPTED MANUSCRIPT}




\section{ACCEPTED MANUSCRIPT}

scenario, nearly $43 \%$ of the global energy of the Middle East region can be supplied from renewable and nuclear energies by 2100 . Natural gas plays main role in the future of energy supply system in this region. It is evident that the switching from baseline to zero emission scenario increases the need of natural gas consumption in the power sector $(45 \%$ of total electricity generation by 2100) and by using CCUS, more associated gas will be released and these nations can outweigh the costs associated with constructing and operating the CCUS plants with increasing their gas export in the future.

Acknowledgments:

The authors would like to thank the GCOE program in Graduate School of Energy Science, Kyoto University for the great support and helpful comments.

\section{References:}

Brandt, A.R. Plevin, R.J. and Alexander, E.(2010). Dynamics of the oil transition: Model in capacity, depletion, and emissions, Energy 35:2852-2860

Brandt, A.R. (2010). Review of mathematical models of future oil supply: Historical overview and synthesizing critique, Energy 35:3958-3974

Abu-Qarn, A.S., Abu-Bader, S. (2004) . The validity of the ELG hypothesis in the MENA region: cointegration and error correction model analysis. Applied Economics 36: 1685-1695

BP. (2012). Energy Outlook 2030, London

\section{ACCEPTED MANUSCRIPT}




\section{ACCEPTED MANUSCRIPT}

Boden, T.A., Marland,G. and Andres, R.J. (2011). Global, Regional, and National Fossil-Fuel $\mathrm{CO}_{2}$ Emissions. Carbon Dioxide Information Analysis Center. Oak Ridge National Laboratory, U.S. Department of Energy, Oak Ridge, Tenn., U.S.A. doi 10.3334/CDIAC/00001_V2011

Chedid, R., Kobrosly, M and Ghajar, R. (2007). A supply model for crude oil and natural gas in the Middle East, Energy Policy 35: 2096-2109

Clark, P., Coene, C., Logan, C. (1981). A Comparison of ten U.S. oil and gas supply models, Resources and Energy 3:297-335.

Cornot,S., Appert, O. and Dickel, R. (2003). Marie-Françoise Chabrelie, Alexandre Rojey, The challenges of future cost reductions for new supply options, $22^{\text {nd }}$ World Gas Conference , Tokyo

El Hedi, A. M., Mhenni, M. and Rault, C. (2012). Energy consumption, economic growth and CO2 emissions in Middle East and North African countries, Energy Policy45: 342-349

Eltony, M.N. (1996) . Demand for natural gas in Kuwait: an empirical analysis using two econometric models. Energy Research 20: 957-963.

Farzaneh, H. , Ishihara, K.N., Utama, N.A., Mclelan, B. and Tezuka,T. (2012). An optimization supply model for crude oil and natural gas in the Middle East, Proceedings International Symposium G-COE, Green energy and technology,Springer

Farzaneh, H. and Dashti, M. (2010). Integrated modeling framework for optimizing energy demand in high energy intensive industries in Iran, IEEE International Energy Conference, Bahrain, Manama

\section{ACCEPTED MANUSCRIPT}




\section{ACCEPTED MANUSCRIPT}

Guseo, R. (2011). Worldwide cheap and heavy oil productions: A long-term energy model, Energy Policy, 39: $5572-5577$

German Aerospace Center (DLR). (2005). Concentrating Solar Power for the Mediterranean Region, Stuttgart

International Energy Agency, (2010). World Energy Outlook. IEA. Paris

International Energy Agency.(2011). $\mathrm{CO}_{2}$ Emissions From Fuel Combustion Highlights, 75739Paris Cedex 15. France

International Monetary Found. (2012). http://www.imf.org/external/index.htm

Kiani, B., Pourfakhraei, M.A. (2010). A system dynamic model for production and consumption policy in Iran oil and gas sector, Energy Policy 38:7764-7774

Krichene,N. (2002). World crude oil and natural gas: a demand and supply model, Energy Economics 24: 557-576

Mohamed El Hedi Arouri, Hatem Mhenni, Christophe Rault.(2012). Energy consumption, economic growth and $\mathrm{CO} 2$ emissions in Middle East and North African countries, Energy Policy, 45: 342-349

Nashawi,I.S., Malallah,A. and Al-Bisharah, M. (2010). Forecasting World Crude Oil Production Using Multi cyclic Hubbert Model, Energy Fuels, 24: 1788-1800

Natural Resource Canada. (2012). Long Term Outlook: Crude Oil Prices to 2030, Access Data: www.nrcan.gc.ca

\section{ACCEPTED MANUSCRIPT}




\section{ACCEPTED MANUSCRIPT}

Organization of the Petroleum Exporting Countries. (2011). Annual statistical bulletin. 04750608

Ramakrishnan, R. (2005). An analysis of energy consumption and carbon dioxide emissionsin countries of the Middle East and North Africa, Energy 30: 2831-2842

Sadorsky, P.(2011). Trade and energy consumption in the Middle East, Energy Economics 33: 739-749

Shahbaz ,M. (2012). Multivariate granger causality between CO2 Emissions, energy intensity financial development and economic growth: evidence from Portugal. COMSATS Institude of Information Technology, Lahore, Pakistan. MPRA Paper No. 37774

SABA. (2005). Internal report on ESCO activities in Iran, Tehran

SABA. (2006). Internal report on ESCO activities in Iran, Tehran

Tidball, R., Bluestein, J., Rodriguez, N., and Stu Knoke. (2010). Cost and Performance Assumptions for Modeling Electricity Generation Technologies, NREL

United Nation, Department of economic and social affairs population division, (2012). http://www.un.org/esa/population/

WEC. (2007). Survey of energy resources, 094612126 5.London

WEC. (2008). Energy efficiency policies around the world, Review and Evaluation. Annex 1, Case studies on energy efficiency policy and measures, World Energy Council, London

\section{ACCEPTED MANUSCRIPT}




\section{ACCEPTED MANUSCRIPT}

Wuppertal Institute. (2009). Energy systems in OPEC countries of the Middle East and Norht Africa system analytic comparison of nuclear power, renewable energies and energy efficiency,31.08, Berlin 


\section{ACCEPTED MANUSCRIPT}

Figure1. Modeling framework structure

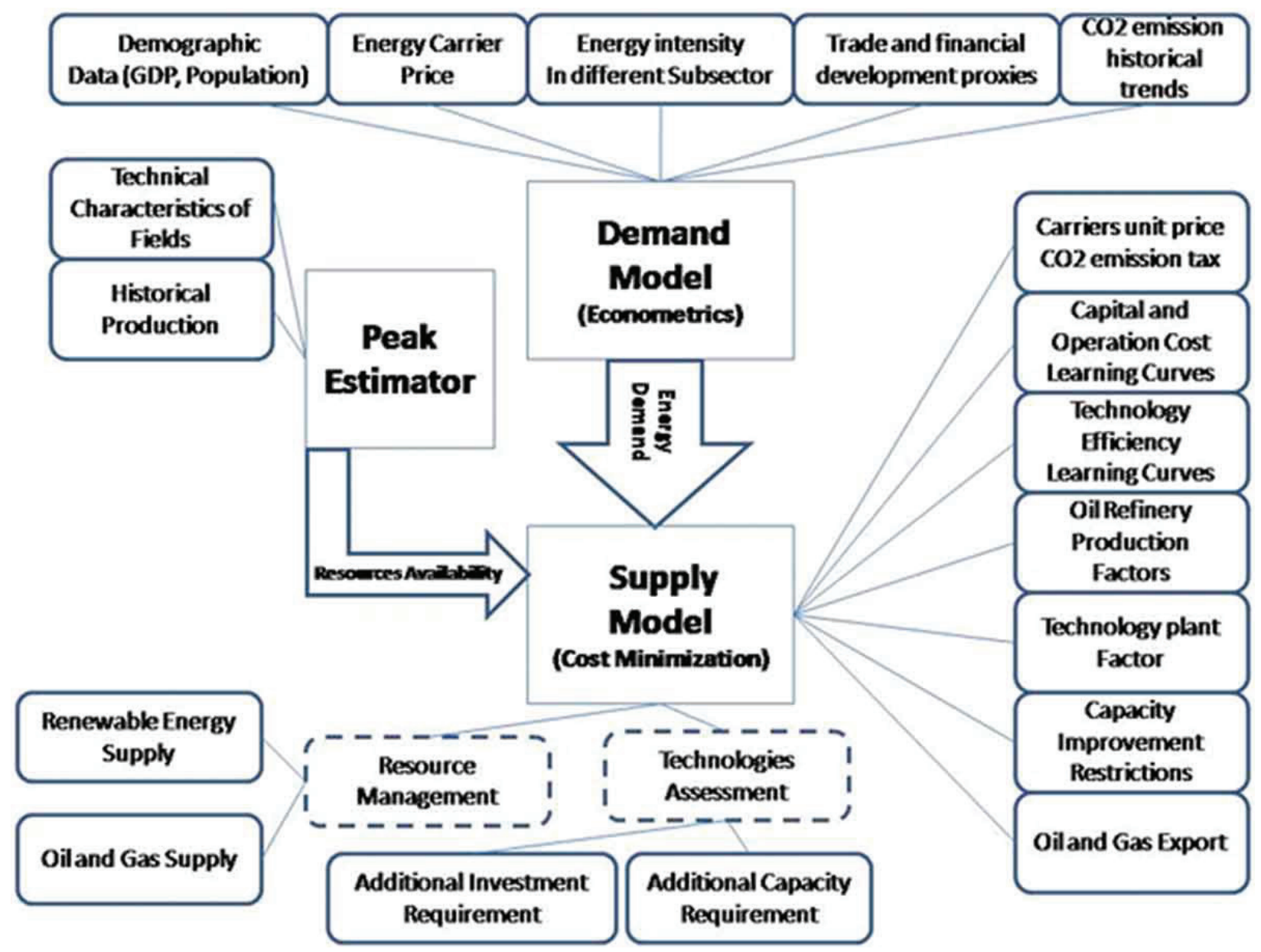




\section{ACCEPTED MANUSCRIPT}

Figure 2. Oil and gas consumption/production in the Middle East selected countries
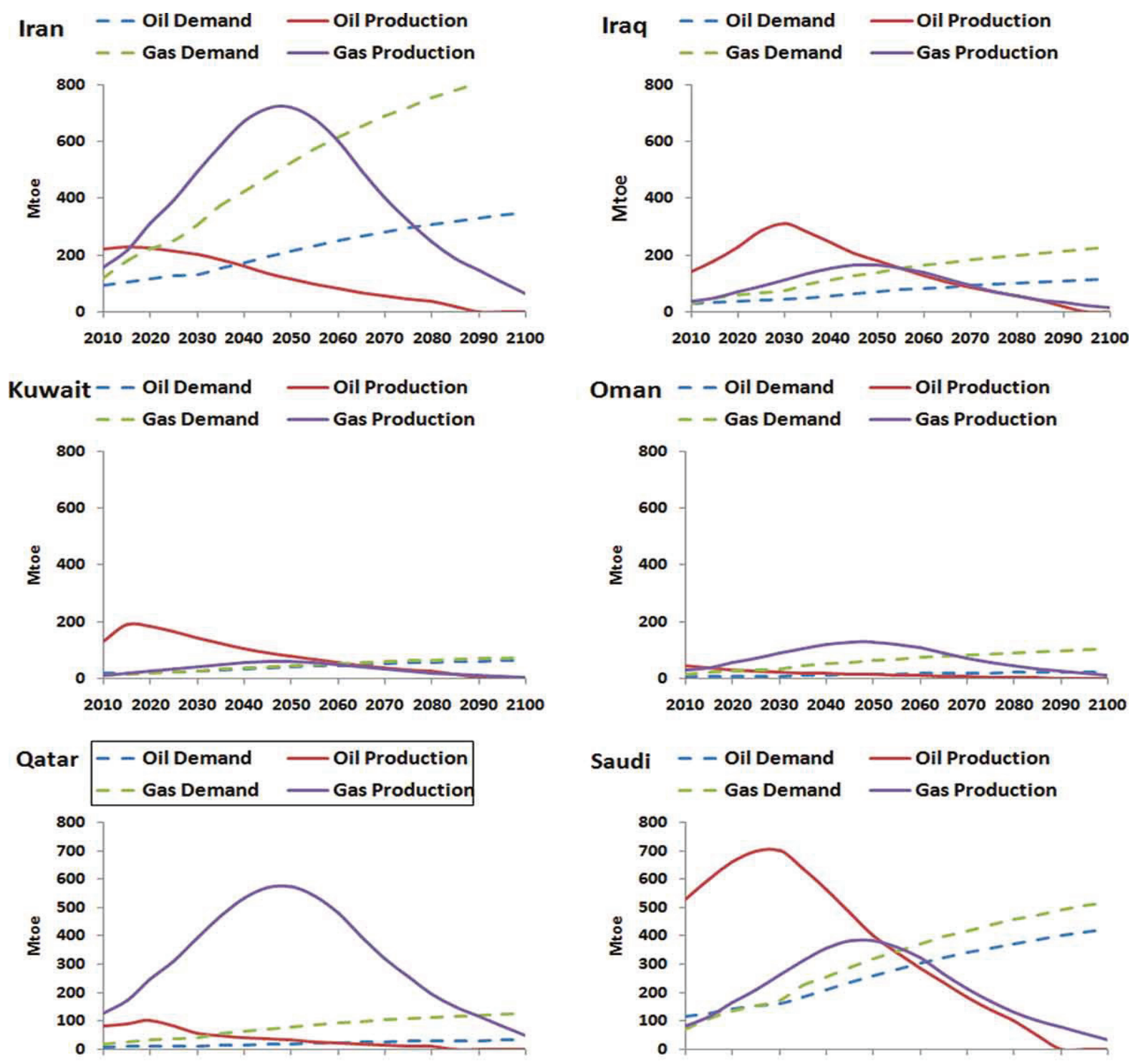

2010202020302040205020602070208020902100
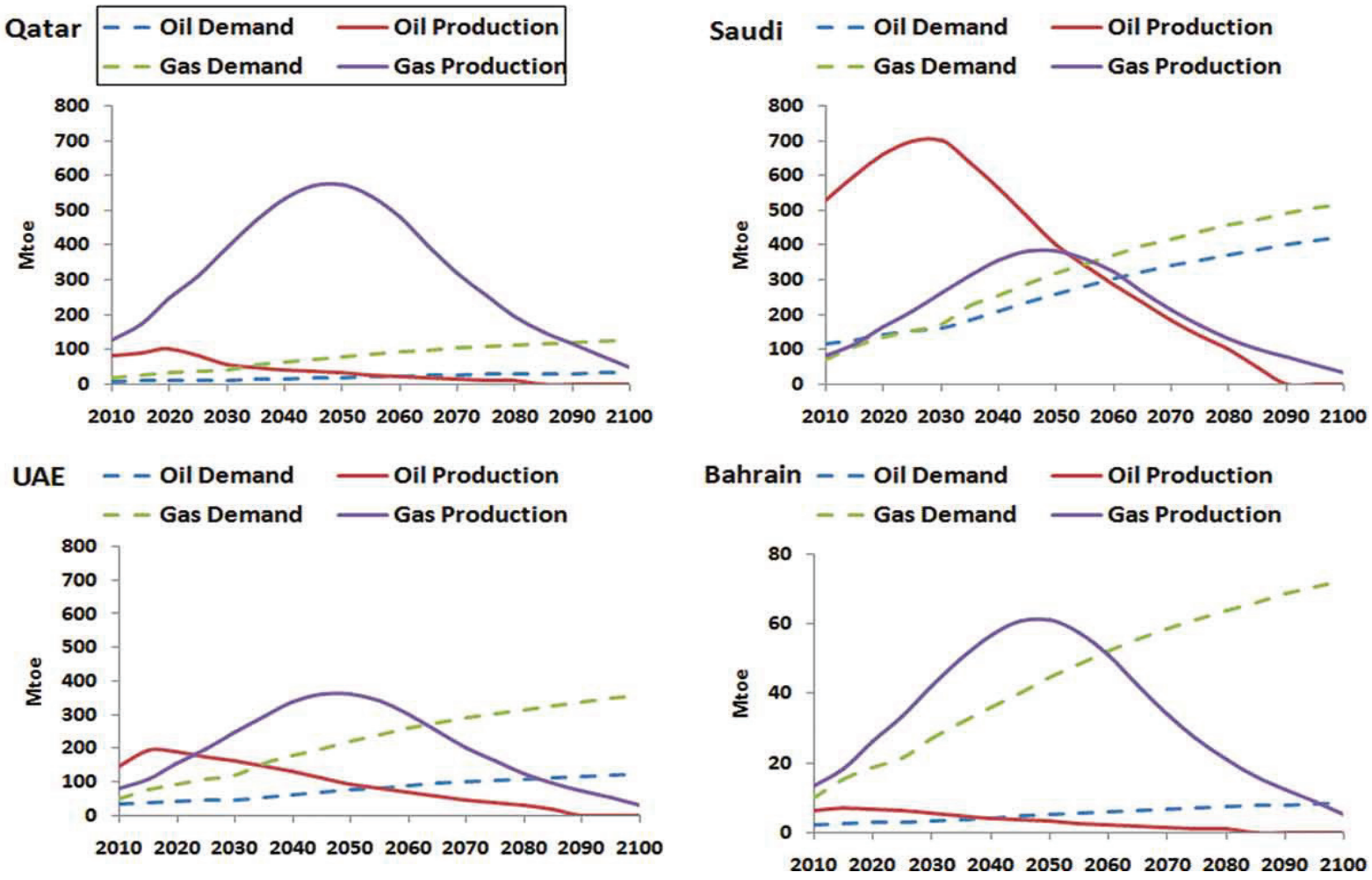


\section{ACCEPTED MANUSCRIPT}

Figure 3. $\mathrm{CO}_{2}$ Emissions and energy intensity projections to 2100

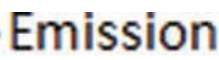

Energy intensity

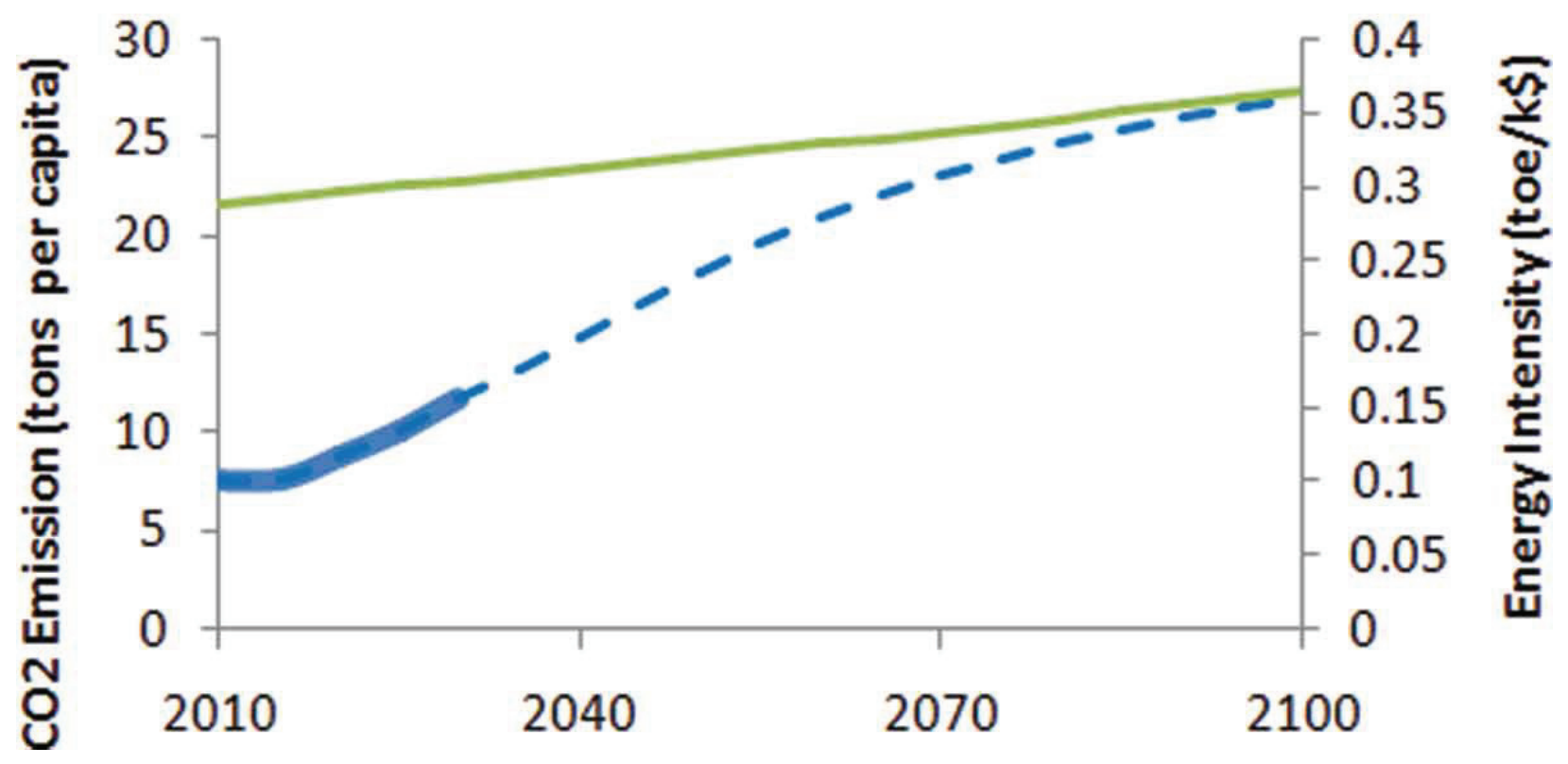




\section{ACCEPTED MANUSCRIPT}

Figure 4. Trend of $\mathrm{CO}_{2}$ reduction in different countries (based on the zero $\mathrm{CO}_{2}$ emissions scenario)

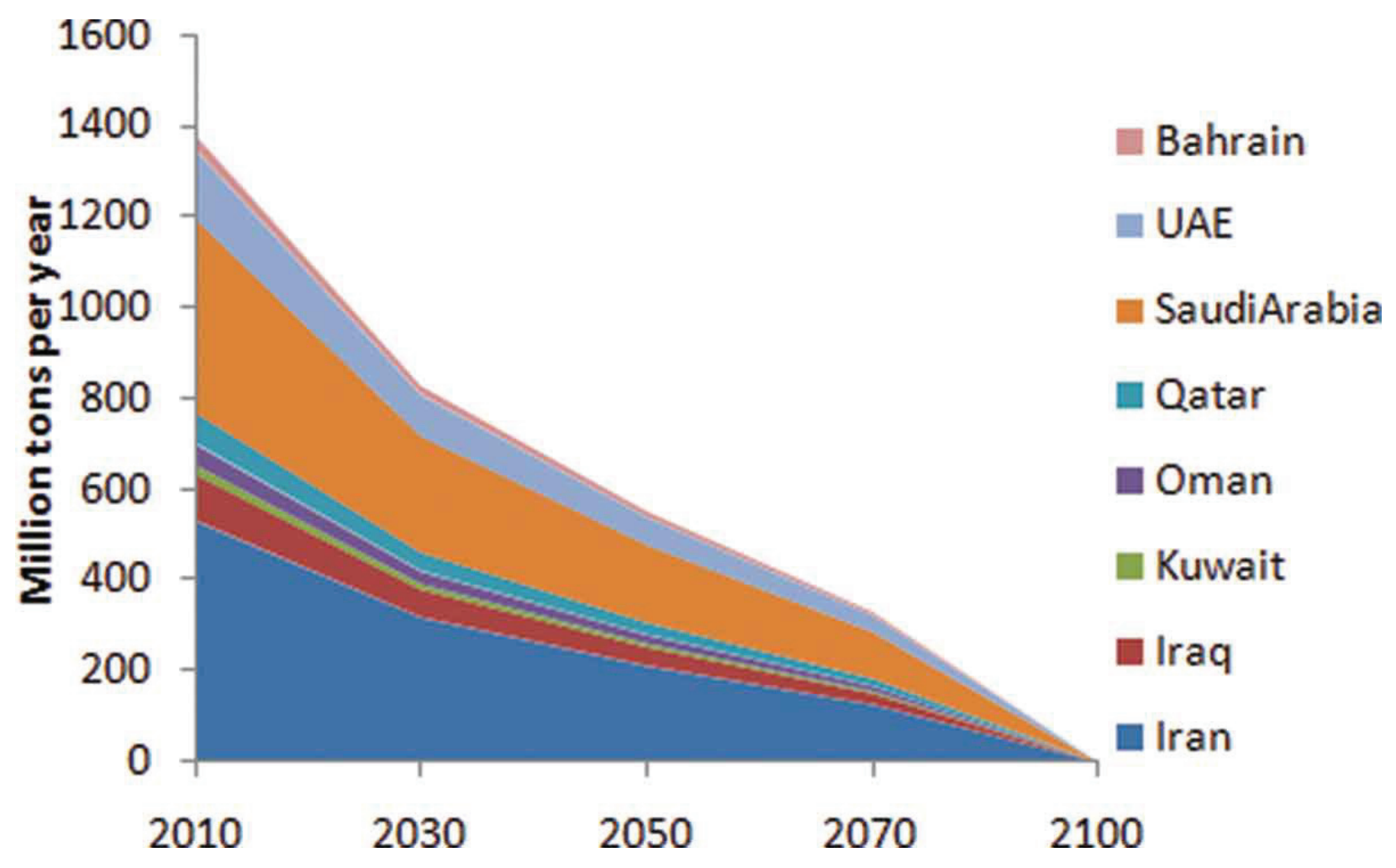




\section{ACCEPTED MANUSCRIPT}

Figure 5.Learning curves of specific investment costs over time

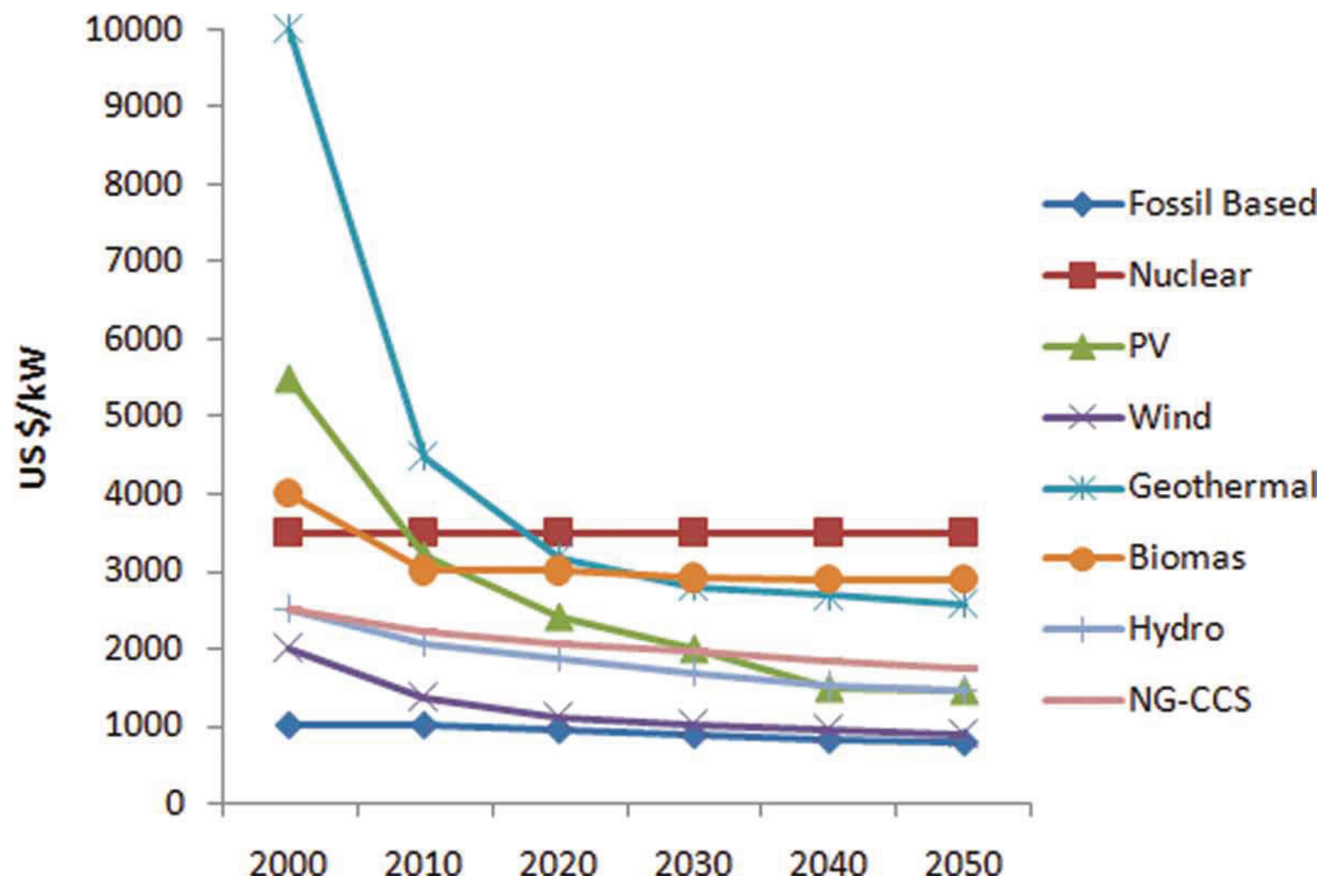




\section{ACCEPTED MANUSCRIPT}

Figure 6. Domestic energy demand in the scenarios

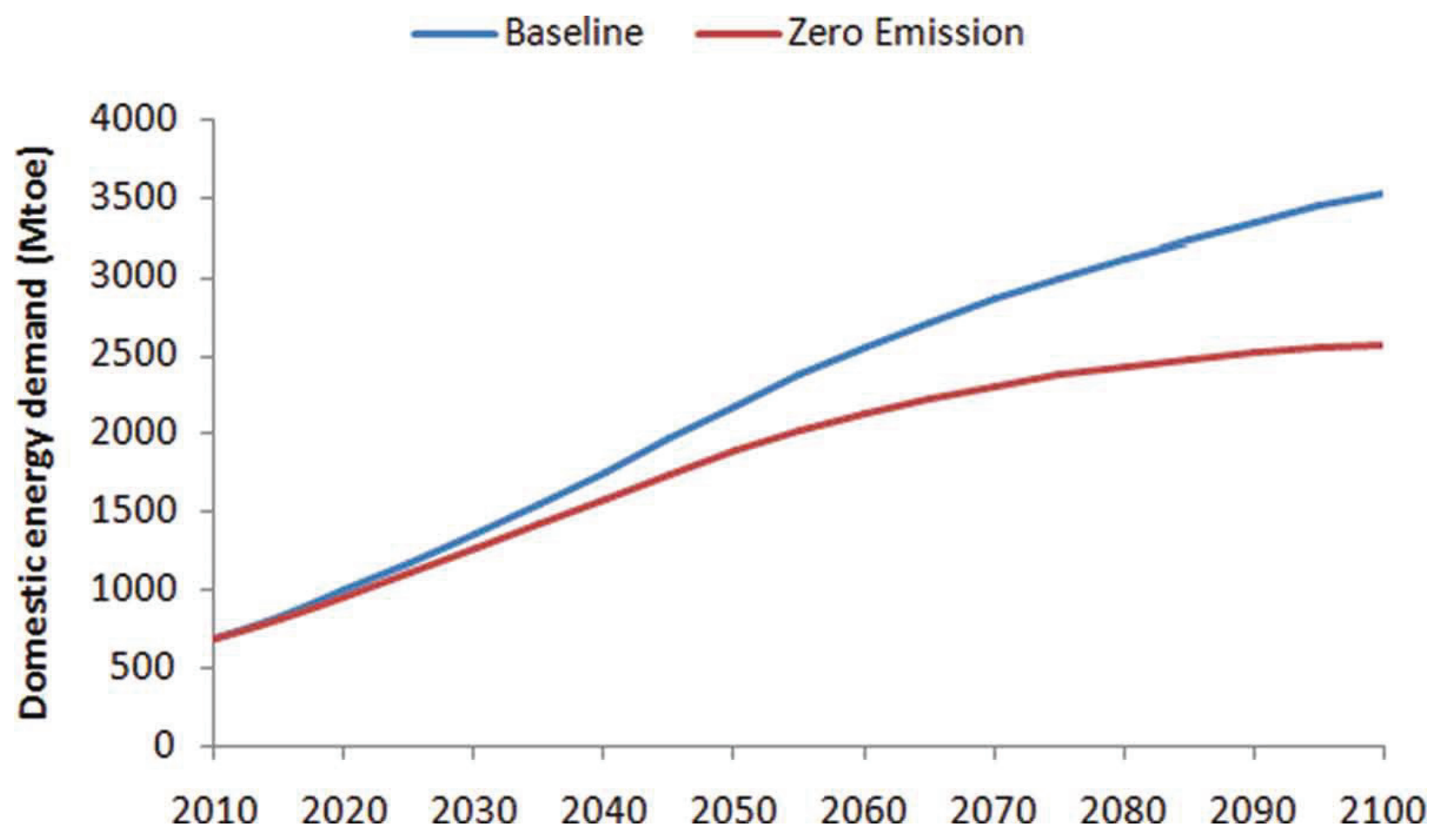




\section{ACCEPTED MANUSCRIPT}

Figure 7. Share of different technologies in the Middle East electricity supply up to 2030

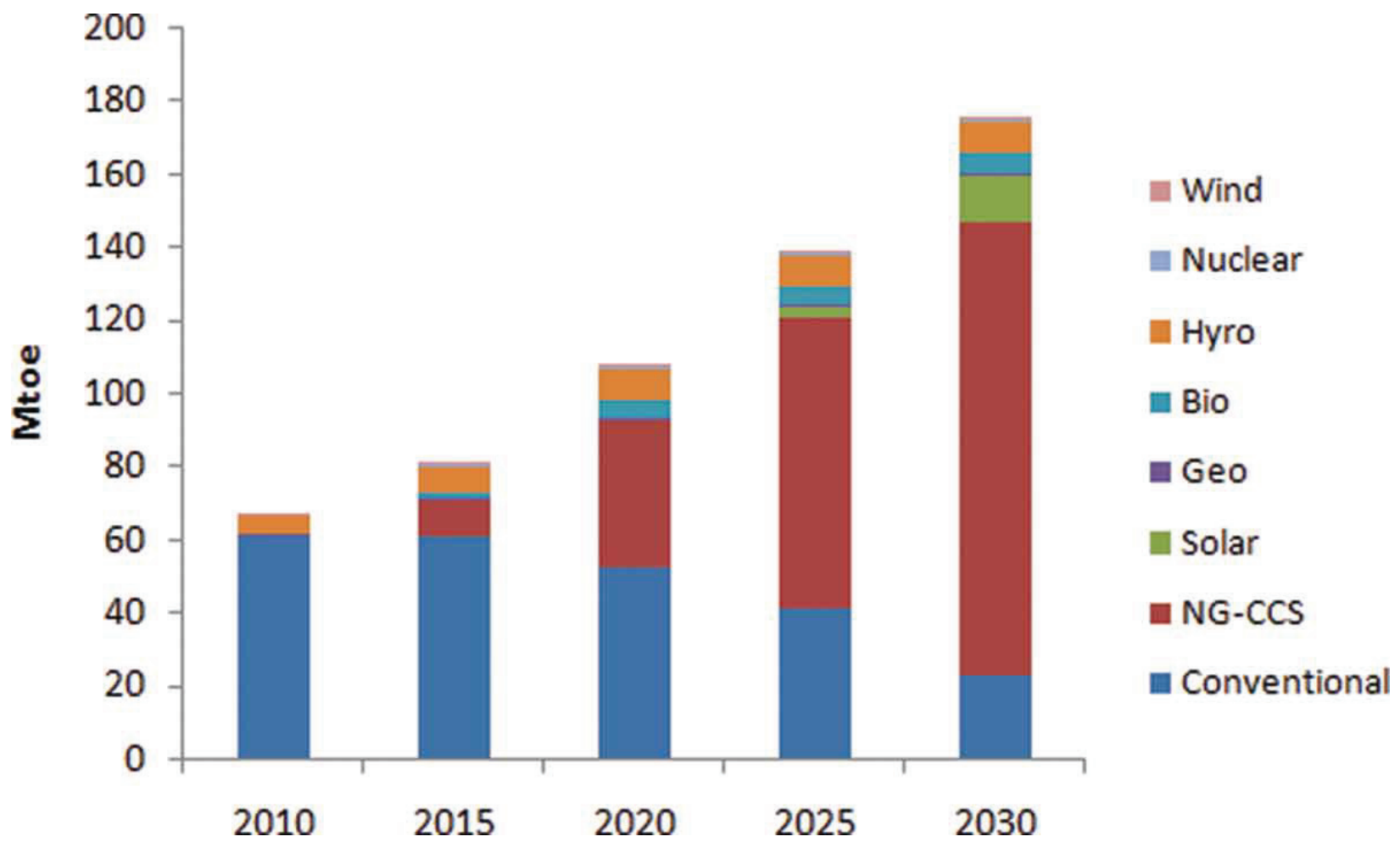




\section{ACCEPTED MANUSCRIPT}

Figure 8. Share of different technologies in the Middle East electricity demand up to 2100

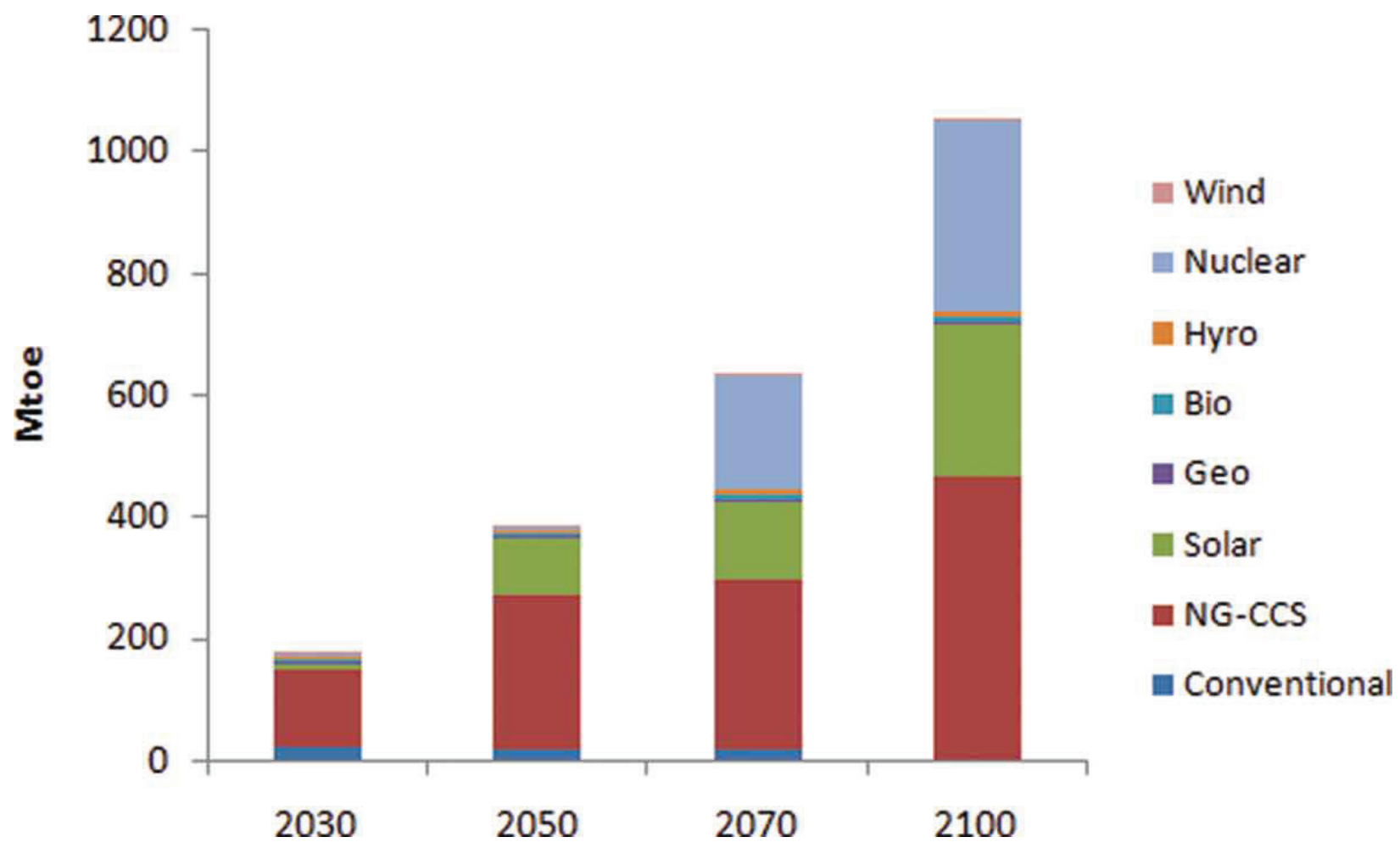




\section{ACCEPTED MANUSCRIPT}

Figure 9. Energy demand mix in the power sectors of selected countries in the zero emissions scenario
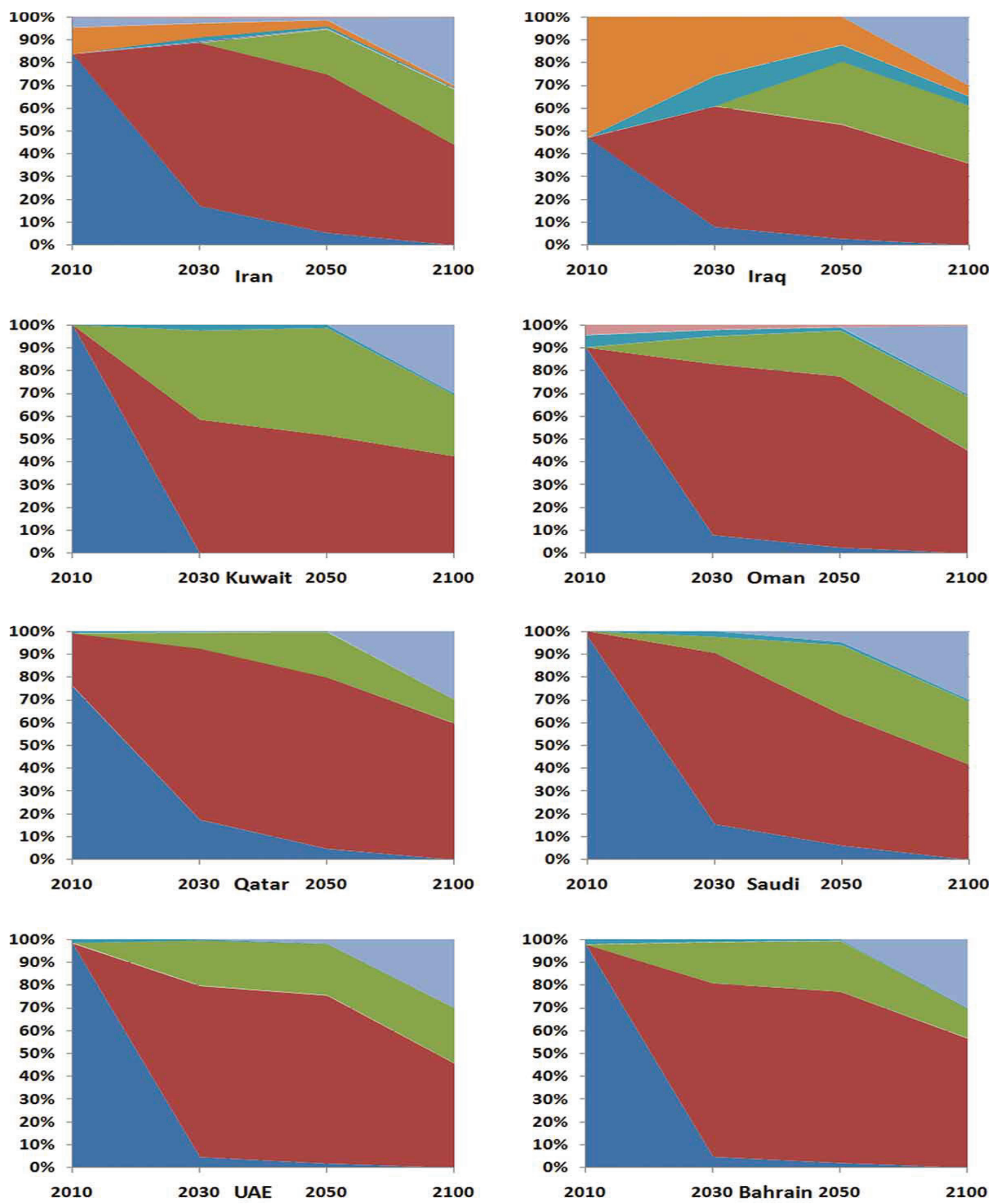

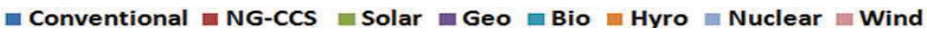




\section{ACCEPTED MANUSCRIPT}

Figure 10. Different modes of natural gas market price projection

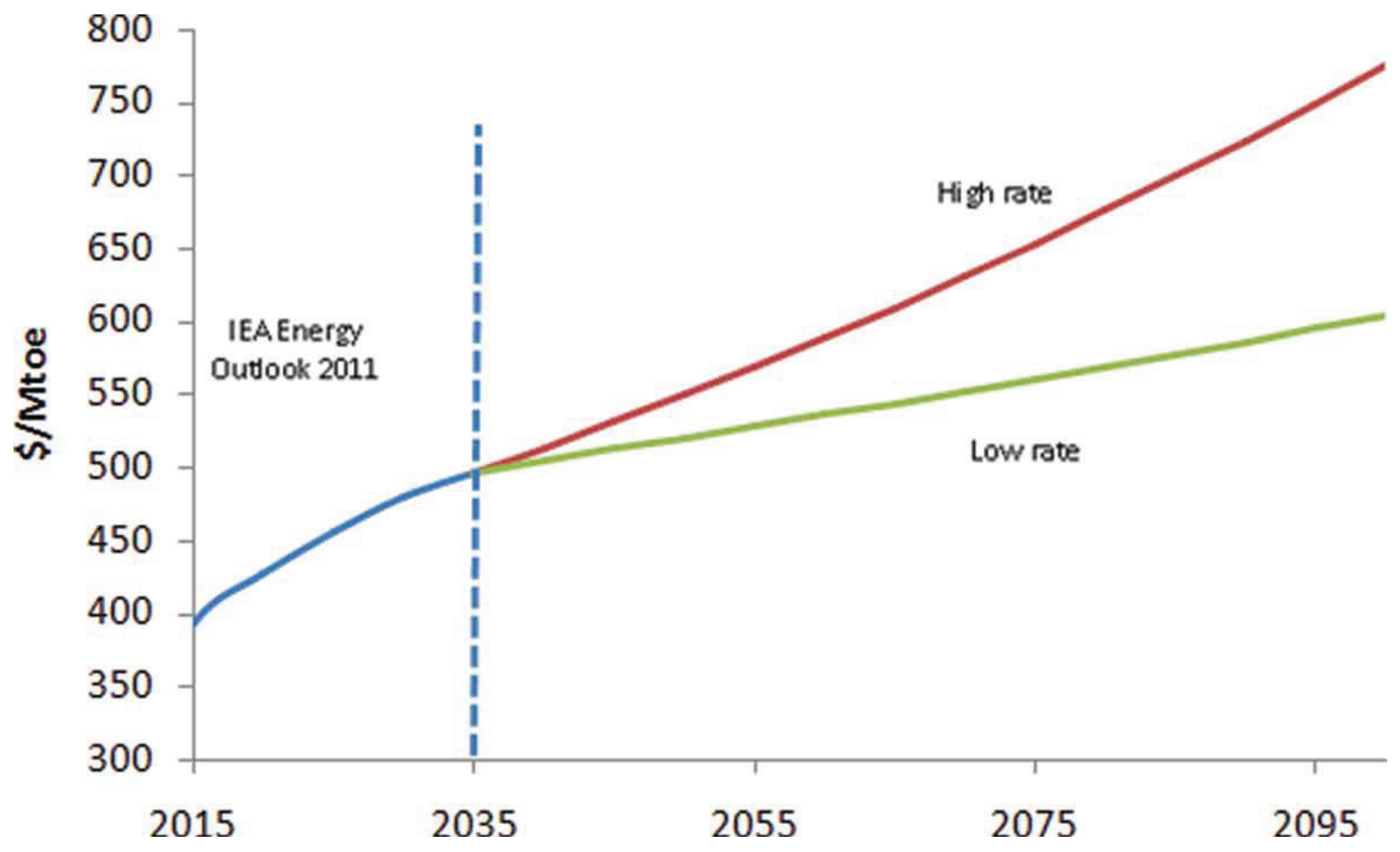




\section{ACCEPTED MANUSCRIPT}

Figure 11. Natural gas export projections based on lower price scenario

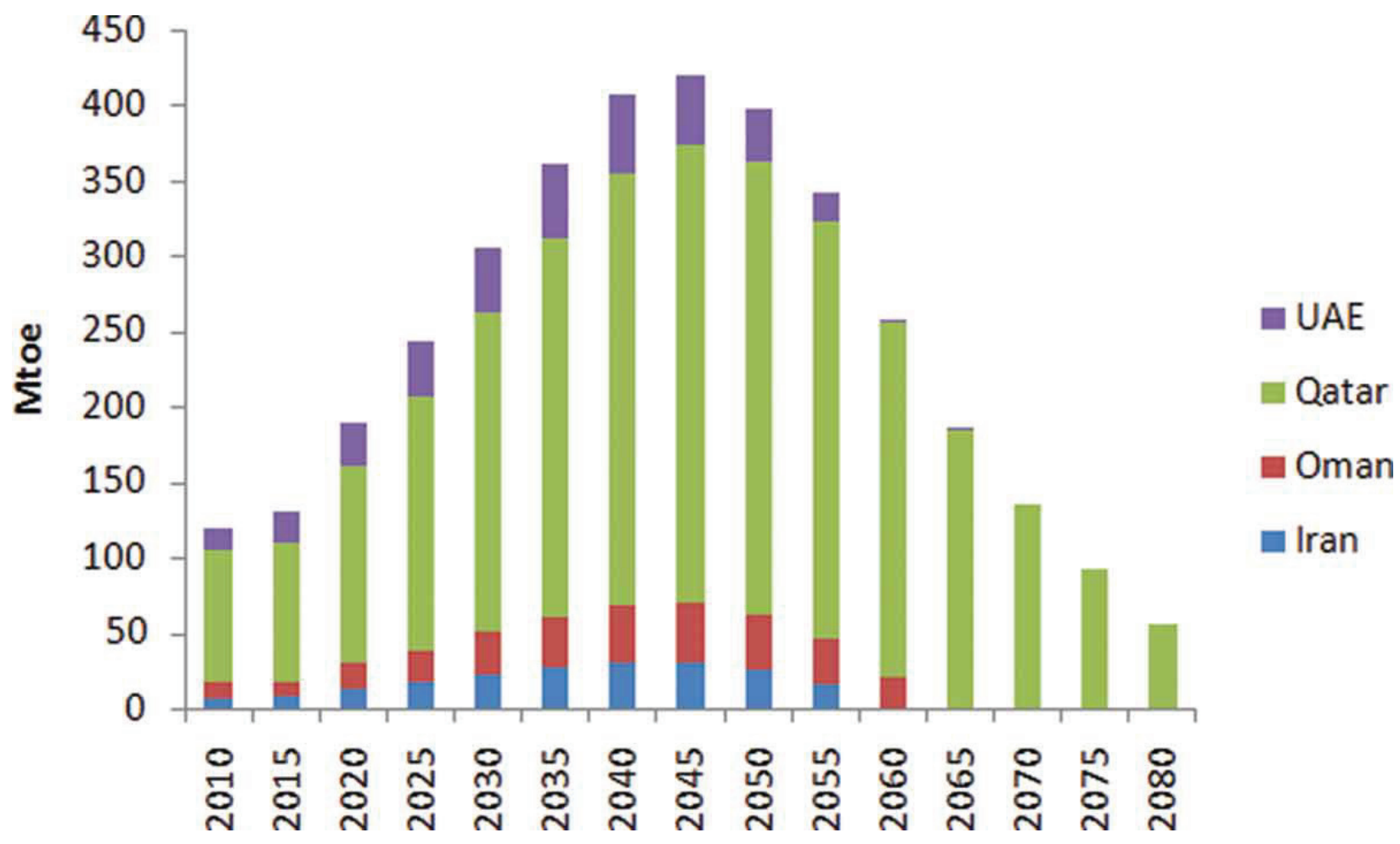




\section{ACCEPTED MANUSCRIPT}

Figure 12. Make up of different technologies in the power sector (High gas price rate)

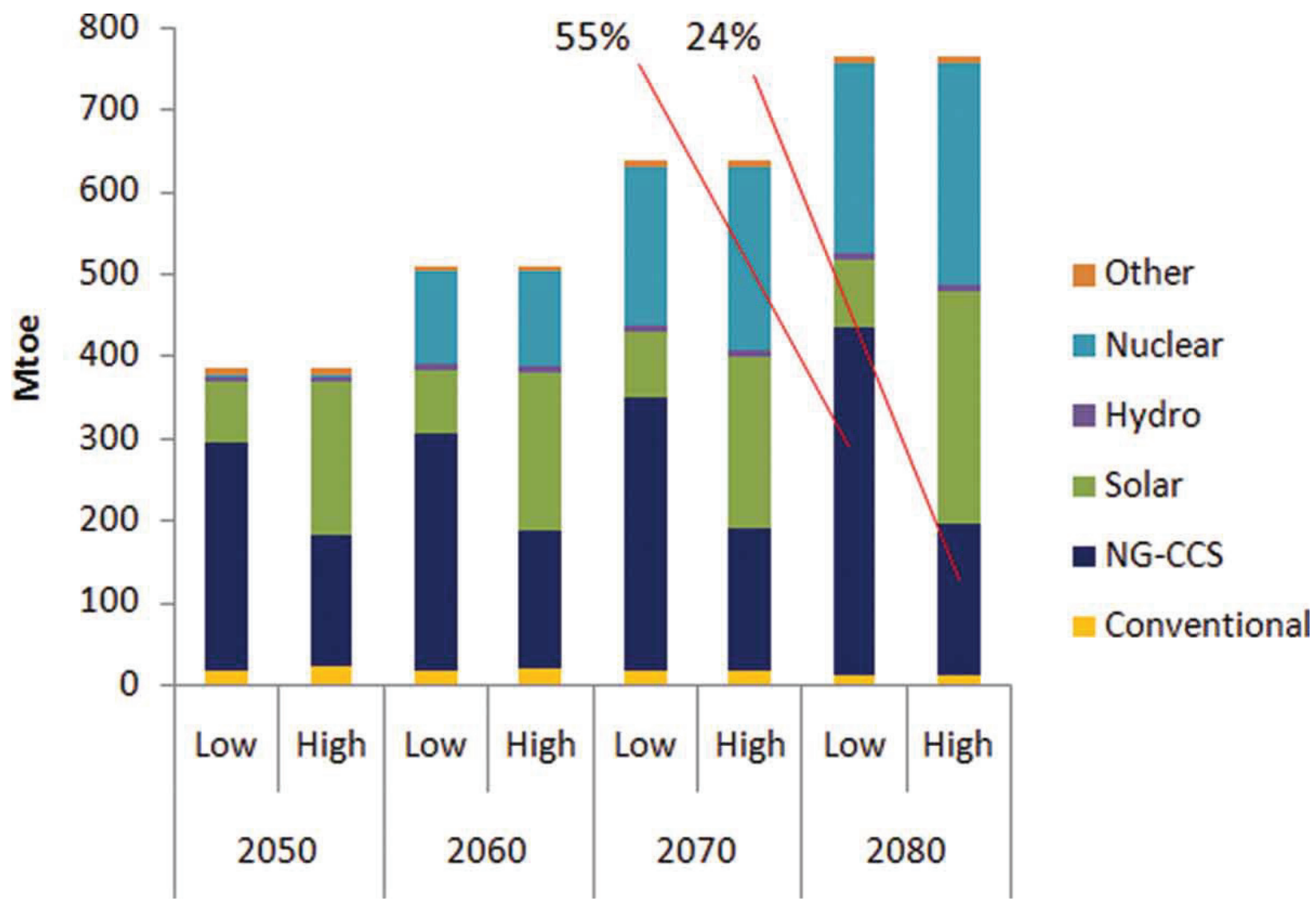




\section{ACCEPTED MANUSCRIPT}

Figure 13. Zero emissions scenario - Middle East region energy supply mix (including oil and gas production for domestic demand, export and also oil products import)

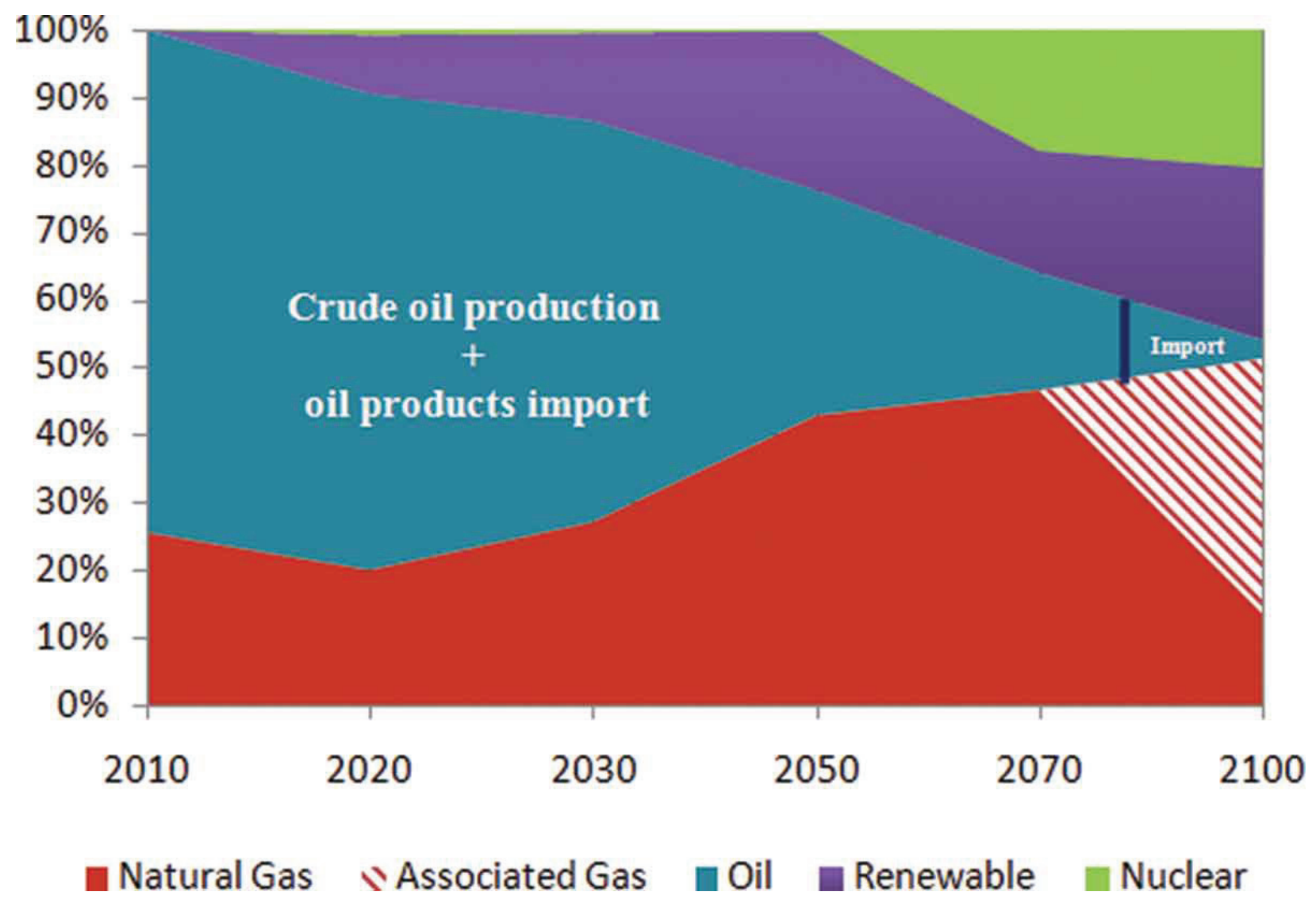




\section{ACCEPTED MANUSCRIPT}

Tab 1. The leading oil and gas producing countries in the Middle East Region (2010)

\begin{tabular}{|c|c|c|}
\hline Country & $\begin{array}{l}\text { Oil Production } \\
\text { (Mbbld) }\end{array}$ & $\begin{array}{c}\text { Gas Production } \\
\text { (bcm) }\end{array}$ \\
\hline Iran & 4.2 & 138.5 \\
\hline Iraq & 2.7 & 1.3 \\
\hline Kuwait & 2.5 & 11.6 \\
\hline Oman & 0.9 & 27.1 \\
\hline Qatar & 1.6 & 116.7 \\
\hline Saudi Arabia & 10.1 & 83.9 \\
\hline UAE & 2.8 & 51 \\
\hline Bahrain & 0.3 & 13.1 \\
\hline Syria & 0.4 & 7.8 \\
\hline
\end{tabular}




\section{ACCEPTED MANUSCRIPT}

\begin{tabular}{|l|c|c|}
\hline Other & - & 17.5 \\
\hline Total Middle East & 25.5 & 460.7 \\
\hline
\end{tabular}

